\title{
Assessment of children presenting with rheumatic complaints to a tertiary center in Turkey: differences in an Eastern Mediterranean population
}

\author{
Ö Bircan Cavkaytar*, A Düzova, Ö Teksam, N Aktay Ayaz, O Derman, \\ A Bakkaloglu, G Kale and S Özen
}

Address: Hacettepe University, School of Medicine, Ankara, Turkey

* Corresponding author

from 15th Paediatric Rheumatology European Society (PreS) Congress

London, UK. 14-17 September 2008

Published: 15 September 2008

Pediatric Rheumatology 2008, 6(SuppI I):PI38 doi:I0.II86/I546-0096-6-SI-PI38

This abstract is available from: http://www.ped-rheum.com/content/6/SI/PI38

(C) 2008 Bircan Cavkaytar et al; licensee BioMed Central Ltd.

\section{Aim}

To evaluate the profile of rheumatic complaints in children in Turkey. The data of the first half of a 6 -month prospective study is presented.

\section{Methods}

Demographic features, medical history, symptoms and signs of children with rheumatic complaints were analysed prospectively in a tertiary health center in central Anatolia. A detailed rheumatologic examination was done. Complete blood counts, ESR, CRP measurement were performed in all patients; other studies were done if necessary.

\section{Results}

From $01^{\text {st }}$ December 2007 to $29^{\text {th }}$ February 2008 , a total of 241 children (M/F: 124/117; mean age $8.0 \pm 4.0$ years) were enrolled. Knee, ankle, hip and wrist were the most frequently involved joints. $61.8 \%$ had rheumatic diseases, and $38.2 \%$ had non-rheumatic diseases. The common causes constituted of familial Mediterranean fever $(12.0 \%)$, other periodic fever syndromes $(2.1 \%)$, HSP $(8.7 \%)$ and other vasculitides $(3.7 \%)$, JIA $(10.0 \%)$, toxic synovitis (6.6\%), rheumatic complaints during the course of an infectious disease (7.9\%), growth pain $(12.9 \%)$, orthopedic problems (18.7\%); acute rheumatic fever $(1.7 \%)$, malignancy $(1.7 \%)$, SLE $(1.2 \%)$, dermatomyositis $(0.4 \%)$, overlap syndrome $(0.4 \%)$ and fibromyalgia $(0.8 \%)$ were rare.

\section{Conclusion}

This is the first study assessing the profile of rheumatic complaints in this part of the world. Our results have showed that auto-inflammatory diseases are strikingly high. Vasculitides and HSP are higher, whereas fibromyalgia is very rare compared to Western Europe. The frequency of ARF has decreased. 